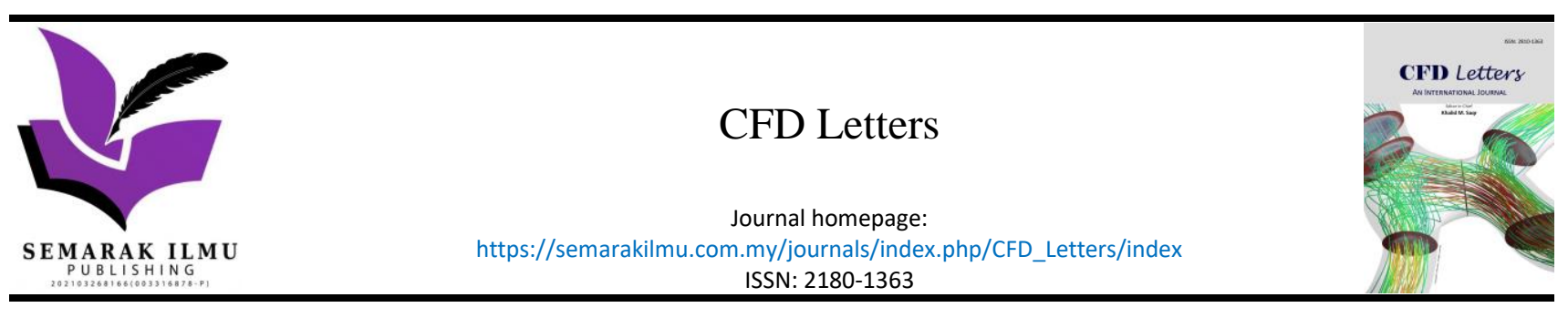

\title{
Computational Fluid Dynamics of Two-Phase Flow Pressure Gradient of Air-Sodium Chloride and Glucose in Horizontal Capillary Channels
}

\author{
Sukamta ${ }^{1,}$, Rama Putrantyo Anwar $^{1}$, Sudarja $^{1}$, Sri Sundari $^{2}$, Mochamad Syamsiro $^{3}$ \\ 1 Department of Mechanical Engineering, Faculty of Engineering, Universitas Muhammadiyah Yogyakarta, Indonesia \\ 2 Department of Medicine, Faculty of Medicine and Health Science, Universitas Muhammadiyah Yogyakarta, Indonesia \\ 3 Department of Mechanical Engineering, Faculty of Engineering, Universitas Janabadra, Indonesia
}

ARTICLE INFO

\section{Article history:}

Received 26 July 2021

Received in revised form 2 December 2021

Accepted 3 December 2021

Available online 7 January 2022

\section{ABSTRACT}

One of the problems in the two-phase flow is investigating the type of flow pattern that occurs in a mini channel without experimenting first. Computational Fluid Dynamics (CFD) is one way that can be used to predict pressure drop, flow pattern, void fraction, other parameters in fluid flow through a channel of a specific size. This research used the CFD simulations to predict the pressure gradient in a two-phase flow of air-sodium chloride $0.9 \%$ and glucose in a horizontal capillary tube with a diameter of $1.6 \mathrm{~mm}$, and length of $70 \mathrm{~mm}$. This research aims to obtain the simulation results of 2D and 3D pressure gradients to validate the experimental data. The simulation was carried out with a variation of the superficial gas velocity 0.1 $-8.3 \mathrm{~m} / \mathrm{s}$ against the superficial velocity of the liquid constant $0.207 \mathrm{~m} / \mathrm{s}$. Simulations were carried out using the Volume of Fluid (VOF) model with the "ANSYS Fluent 2020 R1" software. In 2D and 3D simulations, the gradient values of pressure gradients tend to increase as JG increases. The pressure gradient fluctuates linearly at first, then exponentially from mid-to-end. The findings demonstrate that simulations may properly model physical processes like pattern creation and phase interactions. However, due to several physical elements considered in 3D simulation but missed in 2D simulation, the findings of the $2 \mathrm{D}$ and $3 \mathrm{D}$ simulations were dramatically different when looking at the pressure gradient values.
Keywords: dynamics; glucose; pressure gradient; two-phase flow

\section{Introduction}

According to Faghri and Zhang [1], a two-phase flow is a flow with two different interacting phases, where each phase has its mass or volume in the same channel. One of the most common two-phase flow combinations is liquid and gas flow, where the relative volume fraction of one of the phases causes a different flow system. Examples of applications of a two-phase stream include distillation, spray drying, and absorption processes. In addition, two-phase flow applications can also

\footnotetext{
* Corresponding author.

E-mail address: sukamta@umy.ac.id (Sukamta)
} 
be applied to biomedical engineerings, such as research and development of artificial lungs to absorb oxygen and release carbon dioxide in the blood as needed [1].

The phenomena that occur in two-phase flow include a decrease or increase in pressure. The phenomenon of pressure change is then analyzed in a pressure gradient over a certain distance and time. Much experimental research has been devoted to measuring the pressure drop in the twophase flow of gases and liquids in micro-pipes and channels of circular, square, and triangular crosssections. Experimental studies of pressure drop subsequently yielded newly published correlations [2]. Using empirical methods, computational methods in simulations can provide the necessary variable values using Computational Fluid Dynamics (CFD). Thus, analysis of the results of CFD simulations can be an alternative experiment in the laboratory [3].

Flow pattern predictions in bubble column reactors were predicted using CFD simulations employing 1D, 2D, and 3D models. A full connection between the operation of a genuine column and the simulation has been attempted. Because of their widespread use in the industry, cylindrical bubble columns have gotten a lot of attention. Using 1D, 2D, and 3D models, the CFD model has been extended to estimate an axial dispersion coefficient. Only the experimental values and the 3D predictions showed excellent agreement. The 1D and 2D simulations, on the other hand, produced results that were 25-50 percent lower. A mechanical explanation has been proposed for this [4]. Accurate CFD prediction can be used for various adiabatic and diabetic two-phase discharges in liquids, gases, or particles [5].

Two-phase flow simulations can be performed with varying fluid and line particle sizes. CFD modeling can be applied to nanoscale fluids with particle sizes up to $33 \mathrm{~nm}$ in mini channels [6]. The mini channel is a pipe with a diameter range of $200 \mu \mathrm{m}-3 \mathrm{~mm}$ [7]. For example, the human coronary artery has a 2.1-6.5 $\mathrm{mm}$, including the mini-duct size [8]. Therefore, the two-phase flow model in the minivan can represent human blood flow, as in the study of Sharan and Popel [9]. Their study was carried out with the assumption that the viscosity in the cell-free layer differs from that of plasma due to the additional dissipation of energy near the wall caused by the movement of red blood cells near the cell-free layer.

One of the studies using CFD is a study conducted by Sukamta [10]. This work presents a unique relationship between computational and experimental data for two-phase flow in a small pipe with low fluid viscosity. Before doing an experimental investigation, computational fluid dynamics must anticipate the occurrence to obtain the predicted appropriate outcome. A two-dimensional horizontal capillary pipe with a diameter of $1.6 \mathrm{~mm}$ and a length of $100 \mathrm{~mm}$ was used in the simulation. The simulation employed air-water with varying concentrations of glycerin $(0 \%, 10 \%$, $20 \%$, and $30 \%$ ), as well as liquid superficial velocity $\left(\mathrm{J}_{\mathrm{L}}\right)=0.03 \mathrm{~m} / \mathrm{s}-4.9 \mathrm{~m} / \mathrm{s}$ and gas superficial velocity $\left(J_{G}\right)=9.6 \mathrm{~m} / \mathrm{s}$. In comparison to the simulation, the experimental research employed the same parameter. The results indicated a good match between simulation and experimental data for slug-annular, annular, and churn flow patterns. The viscosity considerably impacts the amount of liquid that adheres to the pipe's inner walls. The higher the viscosity of the liquid, the more it will swell and become trapped in the inner pipe wall.

The general equation of pressure gradients is as follows:

$$
\left(-\frac{\mathrm{d} P}{\mathrm{~d} Z}\right)=\frac{g}{g_{c}} \rho_{s} \sin \varphi+\frac{f_{t p} \rho_{t p}\left(v_{m}\right)^{2}}{2 g_{c} d}+\frac{\rho_{s}}{2 g} \frac{\mathrm{d}\left(v_{m}\right)^{2}}{\mathrm{~d} L}
$$

where:

$$
\rho_{s}=\rho_{L} H_{L}+\rho_{g} H_{g}
$$




$$
v_{m}=v_{s L}+v_{s G}
$$

The two-phase flow has a multiplier factor in the pressure equation to predict the magnitude of the pressure drop in each phase, as in the following equation:

$$
\begin{aligned}
& \Delta p_{\text {frict }}=\phi_{l t t}{ }^{2} \cdot \Delta p_{l} \\
& \Delta p_{\text {frict }}=\phi_{g t t}{ }^{2} \cdot \Delta p_{g}
\end{aligned}
$$

Martinelli's multiplier or confectionary factor $\phi_{l t t}{ }^{2}$ and $\phi_{g t t}{ }^{2}$. It is as follows:

$$
\begin{aligned}
& \phi_{l t t}{ }^{2}=1+\frac{C}{X_{t t}}+\frac{1}{X_{t t}{ }^{2}} \quad, \text { to } \operatorname{Re}_{\mathrm{L}}>4000 \\
& \phi_{G t t}{ }^{2}=1+C X_{t t}+X_{t t}{ }^{2}, \text {, to } \operatorname{Re}_{\mathrm{G}}<4000
\end{aligned}
$$

where $X_{t t}$ Martinelli parameters and C magnitude (Table 1 ) depend on the type of flow that occurs as follows:

$$
X_{t t}=\left(\frac{1-x}{x}\right)^{0,9}\left(\frac{\rho_{G}}{\rho_{L}}\right)^{0,9}\left(\frac{\mu_{G}}{\mu_{L}}\right)^{0,1}
$$

\section{Where}

J Superficial Velocity $(\mathrm{m} / \mathrm{s})$

Q flow rate in the pipe $\left(\mathrm{m}^{3} / \mathrm{s}\right)$

A Cross-sectional area of pipe $\left(\mathrm{m}^{2)}\right.$

$\varepsilon$ Void fraction

$\boldsymbol{v} \quad$ Surface tension $(\mathrm{N} / \mathrm{m})$

$d$ diameter of pipa $(\mathrm{m})$

$\mathrm{F} \quad$ Gaya $(\mathrm{N})$

H Head $(m)$

$g \quad$ Gravity $\left(\mathrm{m} / \mathrm{s}^{2}\right)$

$v \quad$ Velocity $(\mathrm{m} / \mathrm{s})$

$\varphi \quad$ slope of the pipe

$\mathrm{L} \quad$ Length of pipe $(\mathrm{m})$

$\rho \quad \operatorname{density}\left(\mathrm{Kg} / \mathrm{m}^{3}\right)$

$\Delta p \quad$ Pressure Drop $\left(\mathrm{N} / \mathrm{m}^{2}\right)$

$\phi_{l t t}{ }^{2}$ and $\phi_{g t t}{ }^{2}$ Martinelli's multiplier
Re Reynolds Number

$x \quad$ Quality

$\mu \quad$ Viscosity (N.s/m)

C magnitude depends on the type of flow $-\frac{\mathrm{d} P}{\mathrm{~d} Z}$ Pressure gradient $\left(\mathrm{N} / \mathrm{m} \cdot \mathrm{s}^{2}\right)$

And the subscribe

$\begin{array}{ll}\text { S } & \text { solid } \\ \text { C } & \text { center } \\ \text { TP } & \text { two-phase flow } \\ \text { L } & \text { Liquid } \\ \text { G } & \text { Gas } \\ \text { m } & \text { mixture } \\ \text { frict. } & \text { friction }\end{array}$

Table 1

Value of $C$ in Martinelli Equation

\begin{tabular}{lll}
\hline Fluid & Gas & C \\
\hline Turbulent & Turbulent & 20 \\
Laminar & Turbulent & 12 \\
Turbulent & Laminar & 10 \\
Laminar & Laminar & 5 \\
\hline
\end{tabular}


On the other hand, the flow of heat and mass transfer from hybrid nanofluids is based on ethylene glycol. As a result, hybrid nanofluids significantly influence flow and temperature [11]. Also, the effects of magnetic dipoles for thixotropic nanofluids with heat and mass transfer and concentrations of microorganisms passing through curved stretching surfaces are discussed. As a result, the dipole and porosity effect decreases speed, while the thixotropic nanofluid parameters increase speed [12]. The characteristics of unstable heat flow and transfer from thin liquid films based on non-Newtonian water-based nanofluids have been studied. By implanting graphene nanoparticles, it effectively strengthens the thermal conductivity of nanofluids. A favorable comparison with a previously published research paper was made to show a correlation for this work. The coefficient of skin friction and Nusselt numbers show validation for the results that show that the thin layer of fluid from the study corresponds to the results reported in the literature [13]. Research has also been conducted related to peristaltic transport induced by sinusoidal running waves in the case of viscous unsupported Newtonian fluids. The long-wavelength approach is used to simplify the equation system $(\mathrm{d}<<1)$. Velocity distributions for fluids and particles are obtained and evaluated numerically. Flow rate, pressure drop, friction force, and shear voltage on the outer and inner walls of the tube are graphically represented. Mathematical analysis of peristaltic flow with application to the ureters in the presence of flexible endoscopes was taken as an actual application in the study. The results obtained are relevant to the transport of other physiological fluids and the industrial applications in which peristaltic pumping is used [14]. The stagnation point of magnetohydrodynamics flows Casson nanofluids towards the stretching surface with speed slips, and convective boundary conditions have been investigated. The effects of different physical parameters on nanofluidic flows' speed, temperature, and concentration have been presented graphically and discussed in detail. Numerical values of the skin friction coefficient, Nusselt number, and Sherwood number are also discussed. It found that fluid velocity decreased with increasing Casson values and suction parameters. By expanding the thermophoresis parameters, the thickness of the momentum boundary layer increases [15].

In contrast to previous research, there are several differences in the study conducted in this paper. The first difference lies in the diameter of the flow channel. The study showed a channel diameter of $1.6 \mathrm{~mm}$ was used. In addition, the research was conducted using a liquid mixture of $0.9 \%$ sodium chloride and $5 \%$ glucose to find comprehensive data on pressure gradients in the flow. Flow pressure is obtained from the flow pattern formed in the simulation. The fluid geometry used is 2dimensional (2D) and 3-dimensional (3D) geometry to determine the difference in the pressure gradient value generated in different dimensions.

\section{Methodology}

The material used is the fluid geometry in the pipe, drawn into two dimensions and three dimensions using the Solidworks 2020 software as in Figure 1, including the mechanical properties of the working fluid. The test section in this simulation is a pipe section with a diameter of $1.6 \mathrm{~mm}$ with a length of $70 \mathrm{~mm}$. 


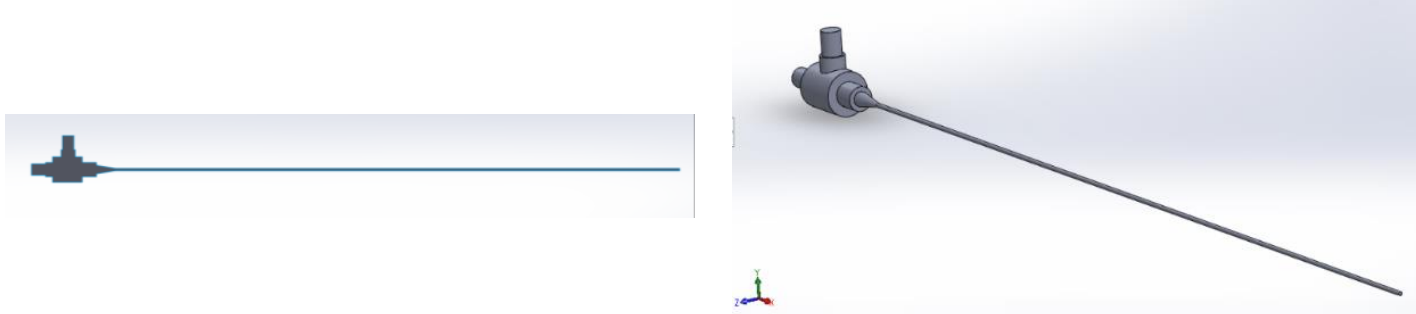

(a)

(b)

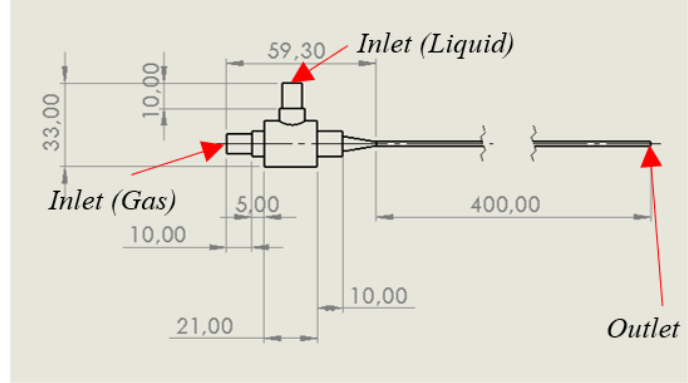

(c)

Fig. 1. Work fluid geometry (a) 2D, (b) 3D, (c) fluid geometry dimensions

Creating fluid geometries can be done using CAD software such as Autodesk Inventor, AutoCAD, and Solidworks, imported into ANSYS Fluent to take the next step. In this study, fluid geometry was created using Solidworks 2020 software. After the fluid geometry is finished, the next step is to make a mesh that divides the plane or volume of fluid geometry into small parts. Mesh making was done using Pointwise V18.3R1 software. This process needs to be done because the calculation method used in CFD is to calculate each part and then add it up to get the desired simulation result. The smaller the mesh size, the more accurate the simulation results will be. The mesh shapes used in this research are quadrilateral mesh for $2 \mathrm{D}$ geometry and hexahedral mesh for 3D geometry. The results of the mesh used in the simulation can be seen in Figure 2. The quality of the mesh is determined by the skewness equiangular value $<0.7$. The quality of the resulting mesh can be seen in Figure 3 . The number of cells in the mesh created is 163,588 elements for 2D geometry and 496,925 elements for 3D geometry.

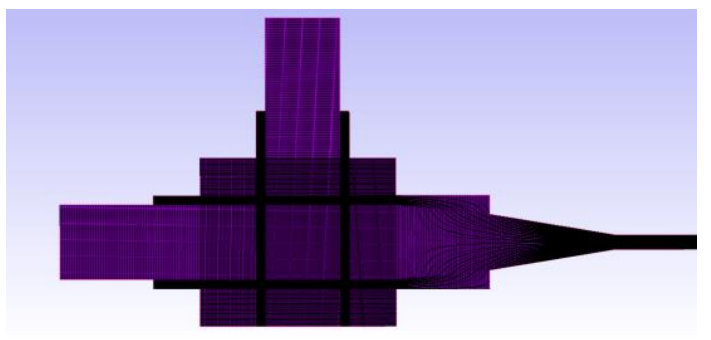

(a)

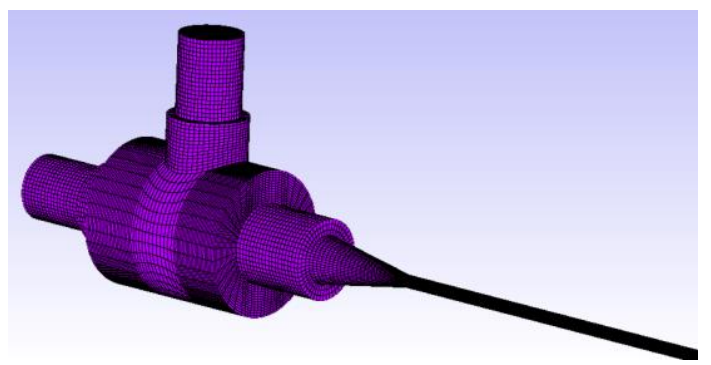

(b)

Fig. 2. The shape of the mesh in (a) 2D fluid geometry and (b) 3D fluid geometry 


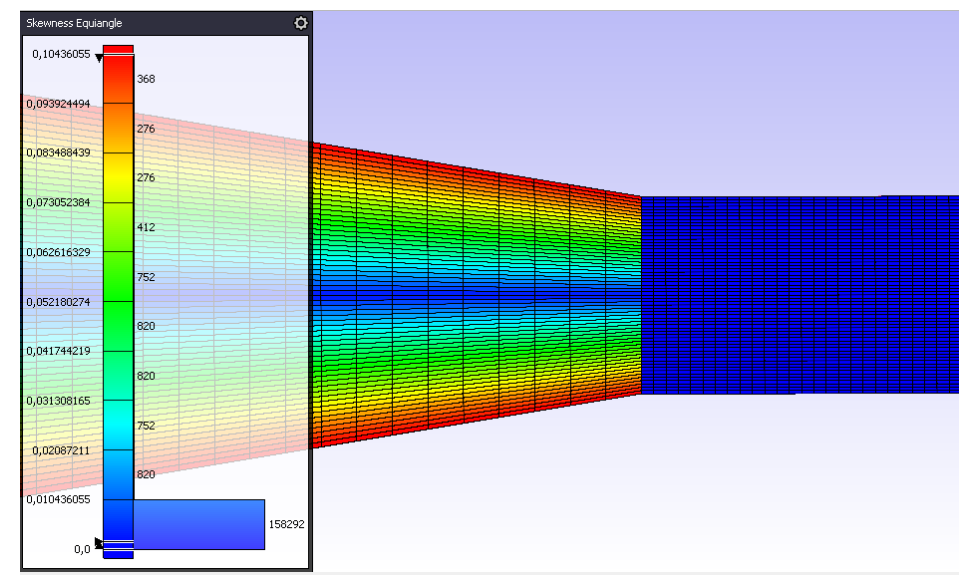

(a)

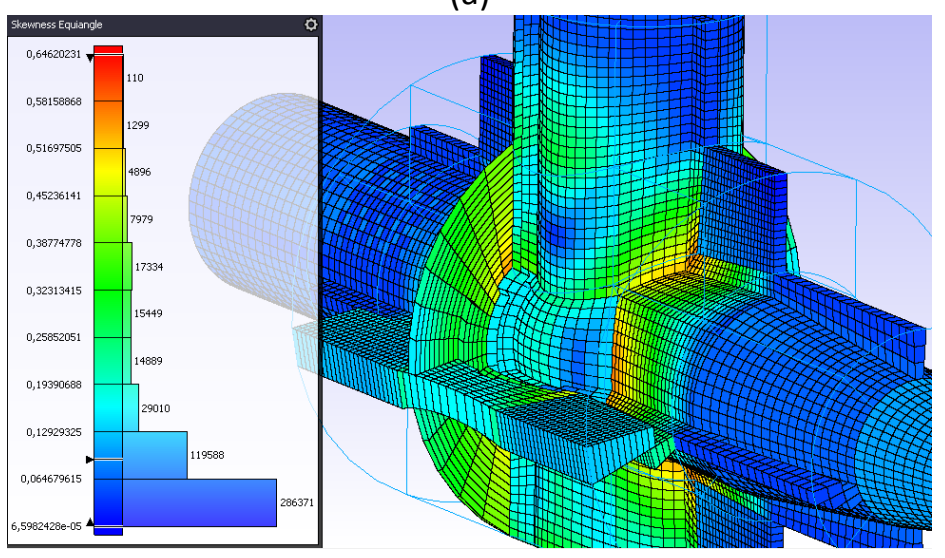

(b)

Fig. 3. Skewness equiangular pada (a) mesh geometry $2 \mathrm{D}$ dan (b) mesh geometry 3D

After making the mesh, a field is defined to determine the location of the boundary conditions. The definitions of the fields in this study include a gas inlet, liquid inlet, outlet, and wall. Next, the processing stage is carried out. The parameters calculations have been determined in the generals, models, surface tension, materials, boundary conditions, solution methods, monitor, and solution initialization section. Suppose the processing stage has been completed without any errors. In that case, the research is continued at the post-processing stage or the last stage of the simulation. The data required in this research are visual data of pressure gradient in flow simulation and pressure result data. Visual data is simulated data in the form of images and is color-coded to indicate a specific value. The data is presented using Image software to see the simulation results obtained. The images processed in ImageJ software are then processed into video format to provide a more precise visualization of the events that occur in the simulation. Pressure data is data obtained from the simulation results on ANSYS Fluent. The data is then processed using Microsoft Excel to see the resulting data on pressure and pressure gradients. Meanwhile, Monitoring the flow pattern in the experiment was done using a Nikon J4 video camera with a speed of $1200 \mathrm{fps}$. At the same time, the simulation is done with automatic recording by fluent software $2020 R 1$.

\section{Results}

The characteristic used in the simulation is a multi-phase flow model. The multi-phase model used is the Volume of Fluid (VOF) model with transient conditions. The simulation will continue until the flow pattern appears in the pipe. The time required for the flow pattern to appear in 2D 
simulations is 0.3 to 1.25 seconds, depending on the variation of the superficial velocity of the gas used. The time step values used in each variation are $1 \times 10^{-5}$ to $1 \times 10^{-9}$ seconds. The greater the gas superficial velocity value, the smaller the time step used must be. The time step value will affect the convergence criteria fulfillment in the simulation to get the desired simulation result data. The number of time steps used in the 2D simulation is around 125,000-time steps, while in 3D simulation, 265,000 -time measures are used. The maximum iteration given at each time step is 20 iterations. The iteration used is sufficient to meet the convergence criteria in the simulation. The convergence criterion used for each equation is $1 \times 10^{-3}$; except for the continuity equation, a convergence criterion of $5 \times 10^{-2}$ is used. The computation time required to run a $2 \mathrm{D}$ simulation of one variation of JG is around 24 to 60 hours, while in 3D simulation, it takes about 11 days. The length of computation time depends on the simulation settings used and the complexity of the calculations in meeting the convergence criteria.

The pressure in the test section is observed when the flow pattern in the test section begins to form. The types of flow patterns adjusted to the flow patterns formed in the experimental experiment are plug, slug-annular, and annular. The contours of the flow patterns are obtained and monitored simultaneously as the simulation progresses. Contour data collection of the flow pattern is carried out every 100 or 200-time steps, depending on each variation's total number of time steps. Flow pattern monitoring is performed to determine when the simulation can be stopped. The fluid volume fraction range on the flow pattern contour can be seen in Figure 4.

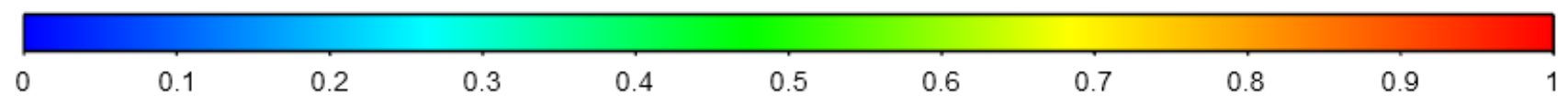

Fig. 4. Volume fraction in simulation

The flow patterns obtained during the simulation are the plug pattern at JG $=0.1 \mathrm{~m} / \mathrm{s}$ and $0.8 \mathrm{~m}$ / $\mathrm{s}$, and the slug-annular pattern at $J_{G}=3.3 \mathrm{~m} / \mathrm{s}-8.3 \mathrm{~m} / \mathrm{s}$. The pattern taken in the simulation is the first pattern that appears. Therefore, the resulting pattern may be different from the pattern from the experimental results. The forms of flow patterns can be seen in Figure 5.

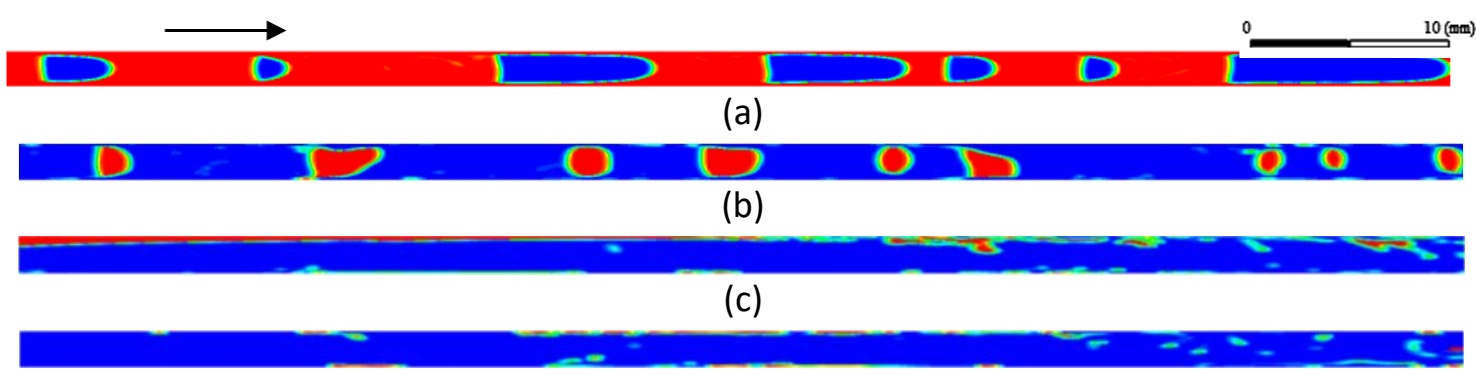

(d)

Fig. 5. Contour of the simulated flow pattern with the variation of $J_{G}$ at $J_{L}=0.2 \mathrm{~m} / \mathrm{s} ;$ (a) $J_{G}=0.1$ $\mathrm{m} / \mathrm{s}$, (b) $\mathrm{J}_{\mathrm{G}}=0.8 \mathrm{~m} / \mathrm{s}$, (c) $\mathrm{J}_{\mathrm{G}}=3.3 \mathrm{~m} / \mathrm{s}$, (d) $\mathrm{J}_{\mathrm{G}}=8.2 \mathrm{~m} / \mathrm{s}$

After the contours of the volume fraction were obtained, a pressure drop analysis was performed. The pressure drop observed in the simulation is obtained from the contours of static pressure and total pressure. Dynamic pressure is not observed in the simulation because it cannot provide a picture of the pressure drop along the pipe required to create a pressure gradient. Contour static pressure or static pressure is observed in the simulation to explain the pressure in the test section. In addition, the static pressure contour also provides an overview of the pressure changes that occur at the variation of each JG concerning the flow pattern that happens. The results of the static pressure 
contour can be seen in Figure 6 . The pressure flowing in the test section continues to increase as the $J_{G}$ value increases.

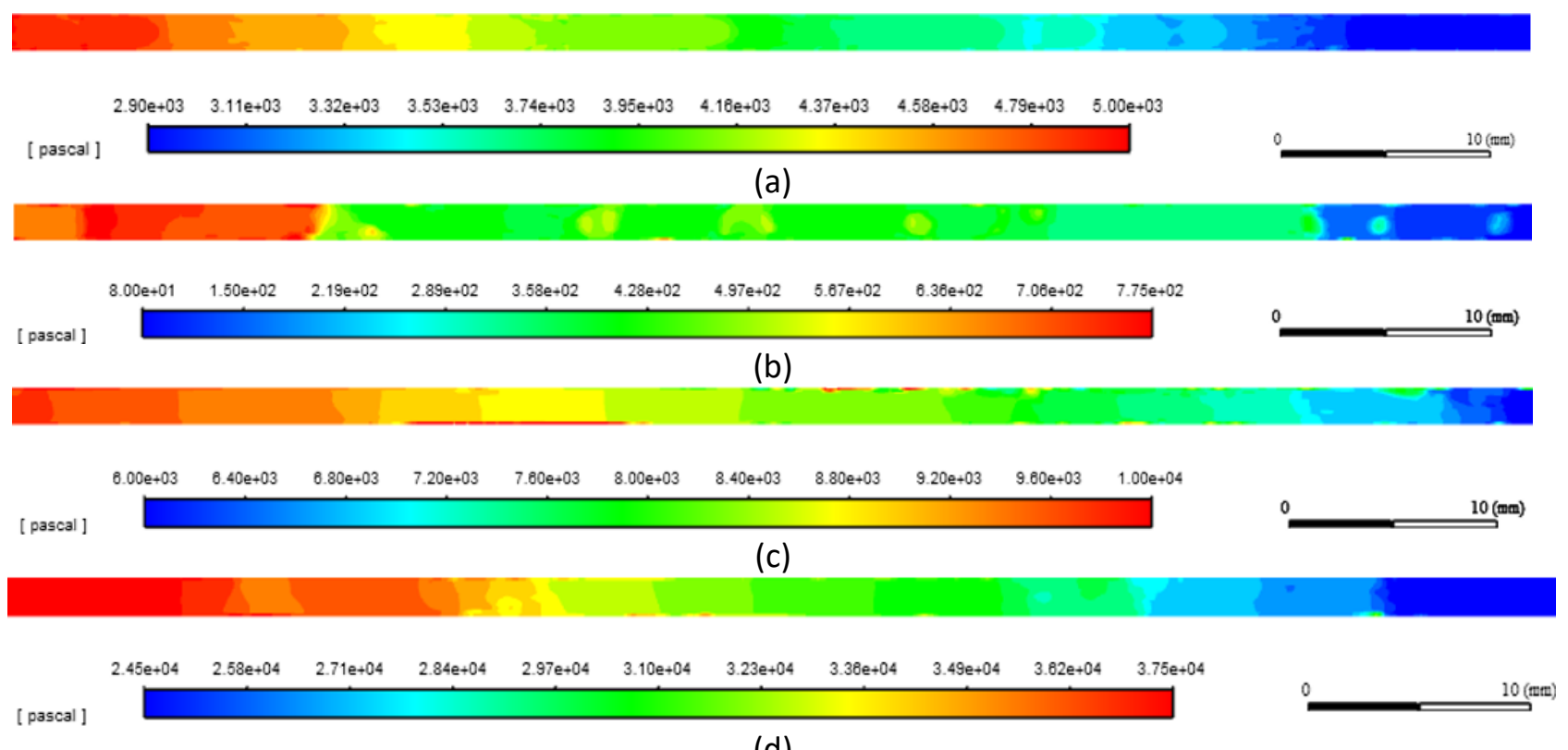

(d)

Fig. 6. Contour of the simulated flow pattern with the variation of $J_{G}$ at $J_{L}=0.2 \mathrm{~m} / \mathrm{s}$; (a) $\mathrm{J}_{G}=0.1 \mathrm{~m} / \mathrm{s}$, (b) $\mathrm{J}_{G}=$ $0.8 \mathrm{~m} / \mathrm{s},(\mathrm{c}) \mathrm{J}_{\mathrm{G}}=3.3 \mathrm{~m} / \mathrm{s}$, (d) $\mathrm{J}_{G}=8.3 \mathrm{~m} / \mathrm{s}$

After a static pressure contour is obtained, a total pressure contour is created. The total pressure is the result of static pressure and dynamic pressure. The total pressure contour in the simulation illustrates the effect of the pattern on the pressure drop in the test section. The pressure spike can be seen in the total pressure contour around the areas that form the flow pattern. The pressure spike that occurs affects the amount of pressure that flows and affects the amount of pressure measured at both ends of the test section. The total pressure contour can be seen in Figure 7.

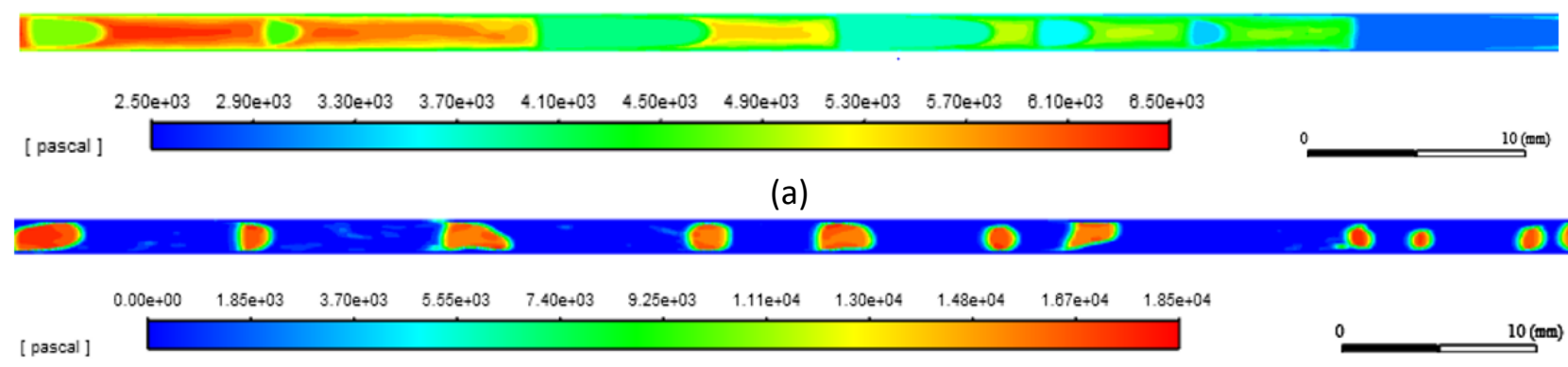

(b)

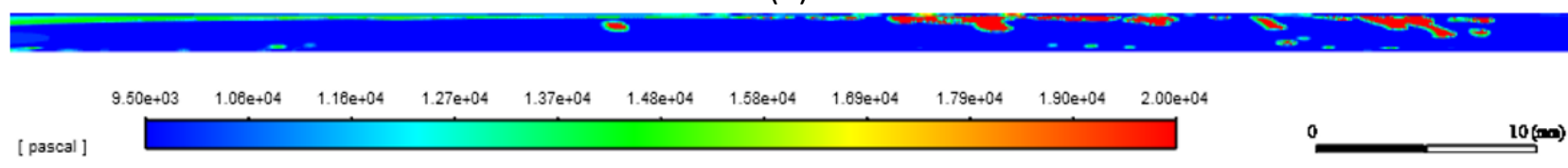

(c)

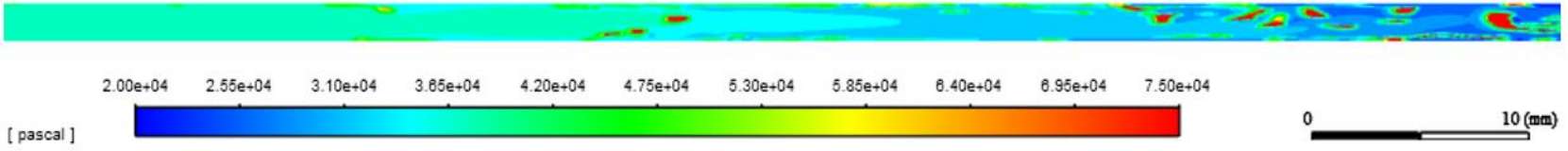

(d)

Fig. 7. The total pressure simulation results with the variation of $J G$ at $J L=0.2 \mathrm{~m} / \mathrm{s} ;(a) J_{G}=0.1 \mathrm{~m} / \mathrm{s},(b) J_{G}=$ $0.8 \mathrm{~m} / \mathrm{s}$, (c) $\mathrm{J}_{\mathrm{G}}=3.3 \mathrm{~m} / \mathrm{s}$, (d) $\mathrm{J}_{\mathrm{G}}=8.3 \mathrm{~m} / \mathrm{s}$ 
After the total pressure contour pressure is obtained, the two ends of the test section are processed into the pressure difference and pressure gradient. First, the pressure gradient is obtained from the difference in the average total pressure or at each end of the simulation test section. The average is obtained because the pressure along the vertical line of the $\mathrm{Y}$-axis of the test section is not the same. Then, the data obtained on each variation is processed into a pressure gradient.

The resulting pressure gradient increases consistently. The pressure gradient data from each variation is then used to create a graph shown in Figure 8.

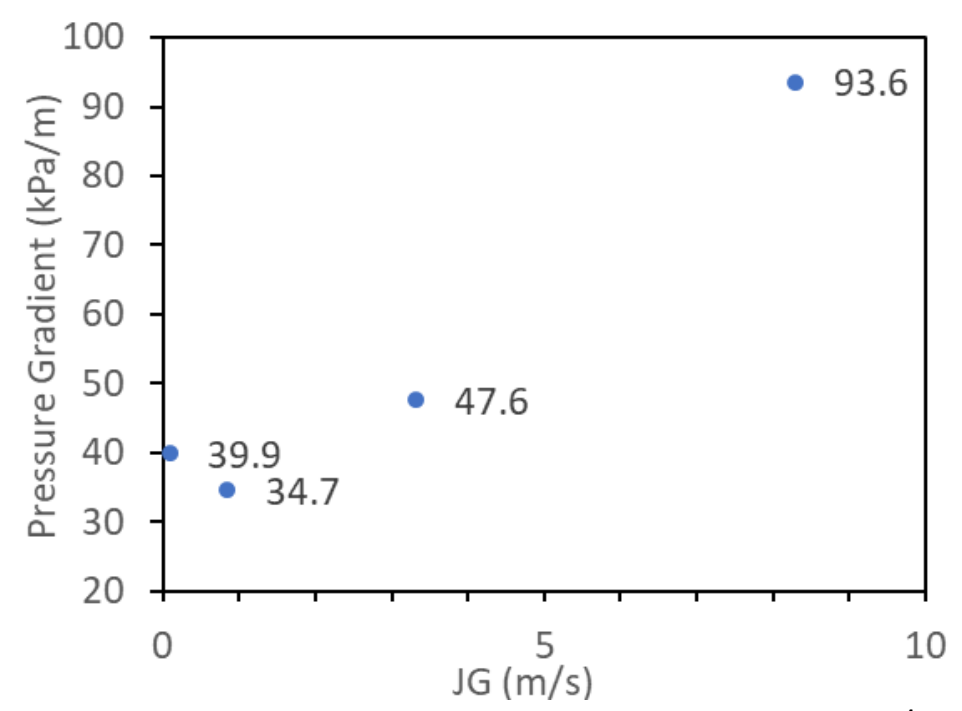

Fig. 8. Pressure gradient on JG variation with $J L=0.2 \mathrm{~m} / \mathrm{s}$

From Figure 8, it can be interpreted that the increase in the pressure gradient from each variation always increases. A decrease in the pressure gradient at $J_{G}=0.8 \mathrm{~m} / \mathrm{s}$, but the decline was not significant. This is possibly due to the influence of the pattern on the variation of $J_{G}=0.8 \mathrm{~m} / \mathrm{s}$, which increases the total pressure value at the end of the simulation test section. The 3D simulation was carried out to explain the difference in the simulation results from the 2D simulation related to the pressure gradient. The difference between 2D and 3D simulations is that flow events on the third axis are ignored in 2D simulations. Geometry in 2D simulation also does not provide the assumption that the cross-section of the tool is circular. 3D simulation was carried out at a variation of $J_{G}=0.083 \mathrm{~m} / \mathrm{s}$. The 2D simulation was completed with a simulation time of 1.25 seconds, while the 3D simulation was met with a simulation time of 2.65 seconds. The difference in simulation time occurs because the formation of flow patterns occurs much faster in 2D simulations. Differences in simulation time can also cause differences in pressure gradient data to be taken. The contours of the 2D and 3D flow patterns are compared to see the pattern formed when the pressure gradient data is taken. Figure 9 shows that the flow pattern contours obtained from the 3D simulation are more defined into plug flow types than 2D simulation.

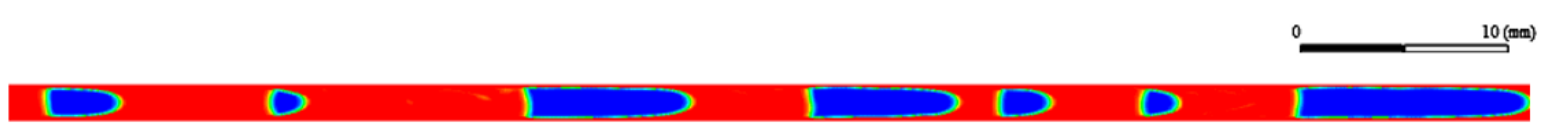

(a)

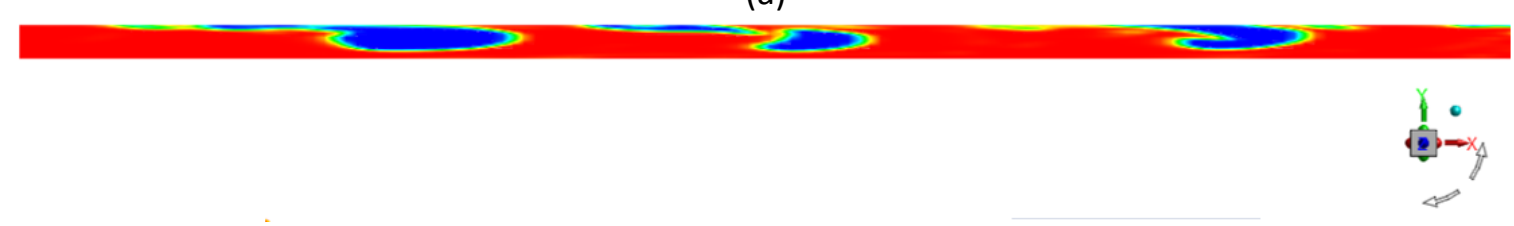

(b) 


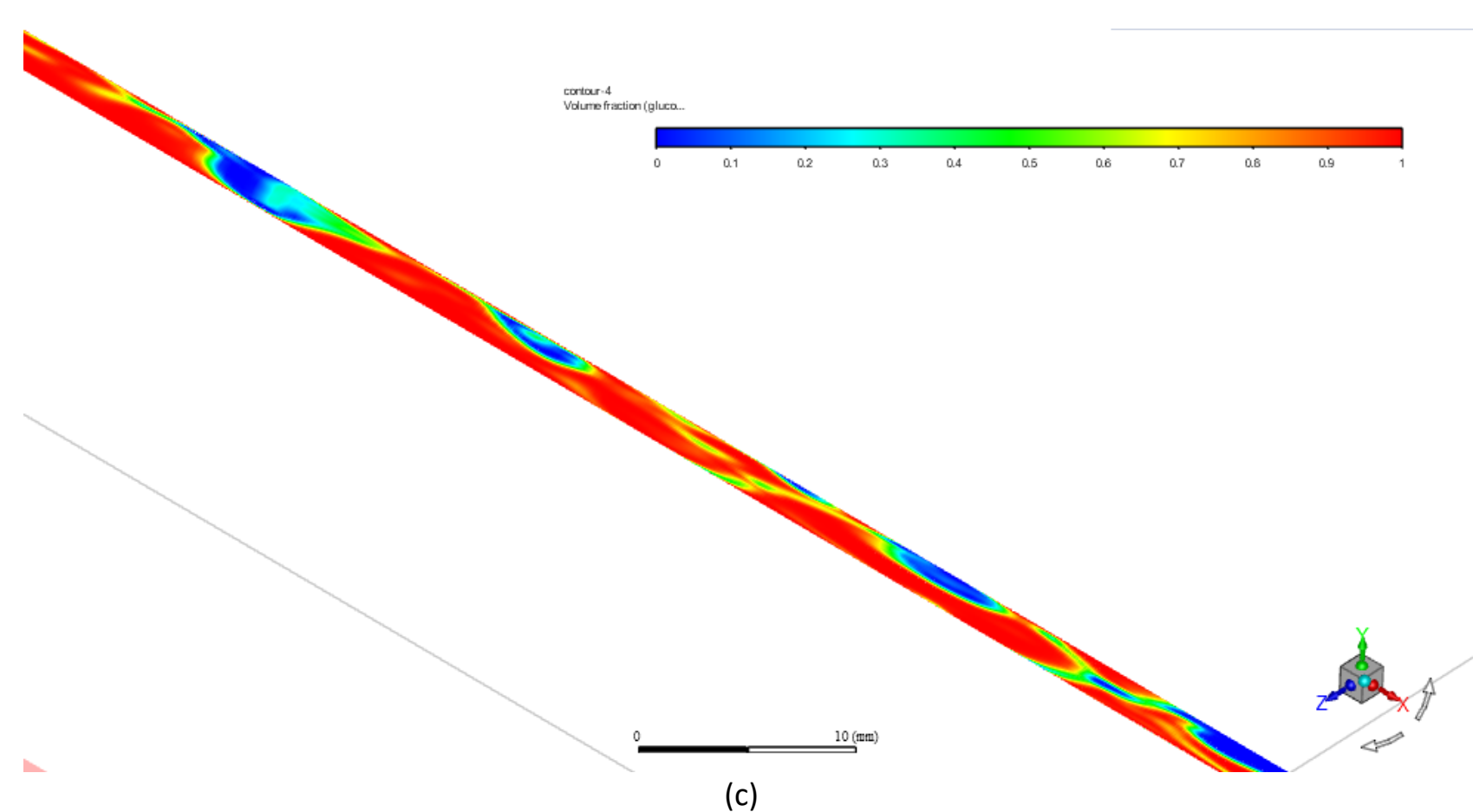

Fig. 9. Contours of flow patterns in (a) 2D simulations and (b) 3D simulations, along with (c) isometric views of flow patterns in 3D simulations

The $2 \mathrm{D}$ and $3 \mathrm{D}$ simulated total pressure contours were compared to see the pressure changes along the test section (Figure 10). The pressure gradient contours of the 2D and 3D simulations have a similar trend of pressure changes, but the amount of pressure flowing has a significant difference.

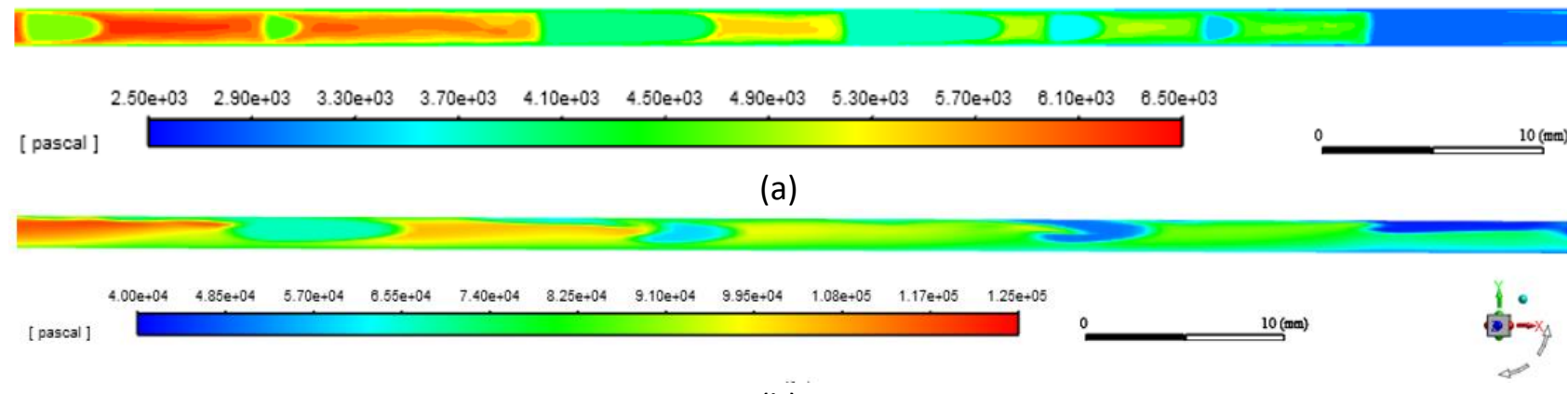

(b)

Fig. 10. The total pressure contour in (a) 2D simulation and (b) 3D simulation

The pressure drop in the 3D simulation is obtained from reducing the average total pressure from the test section's beginning and end. The total pressure contour at both ends of the test section can be seen in Figure 11. 

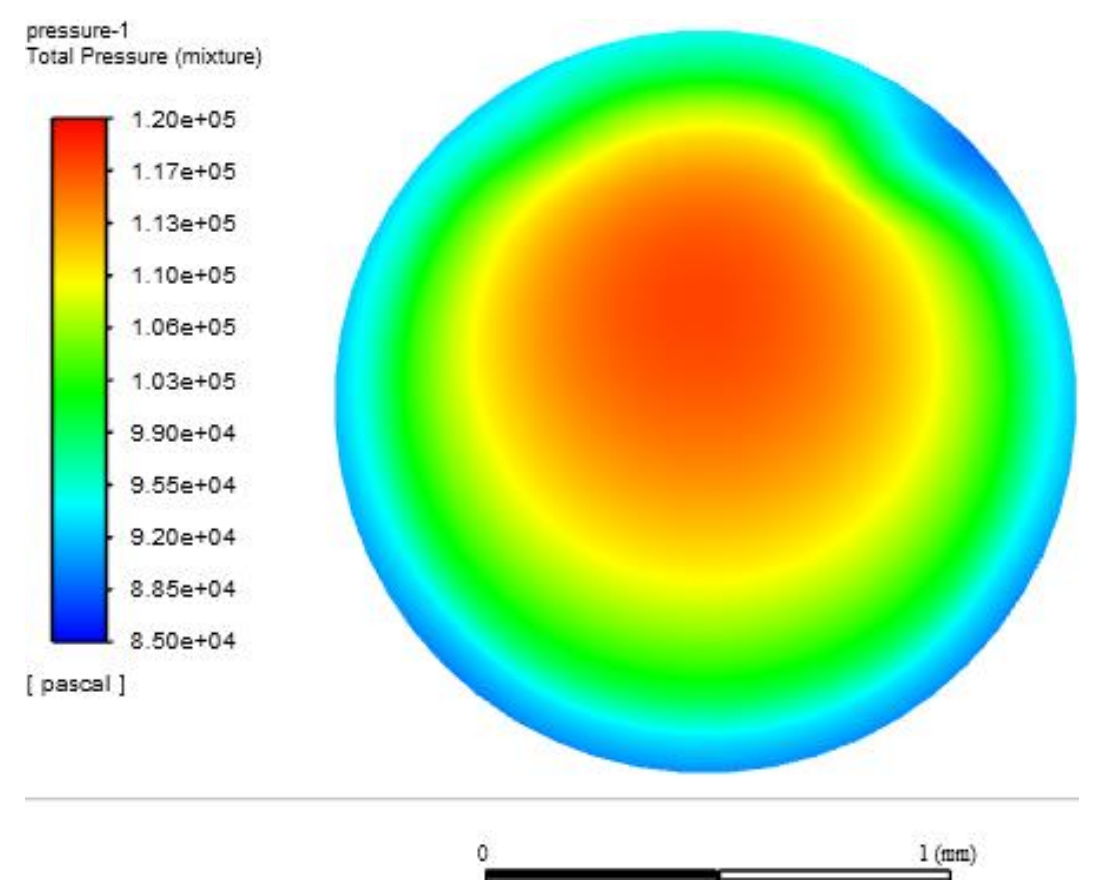

(a)
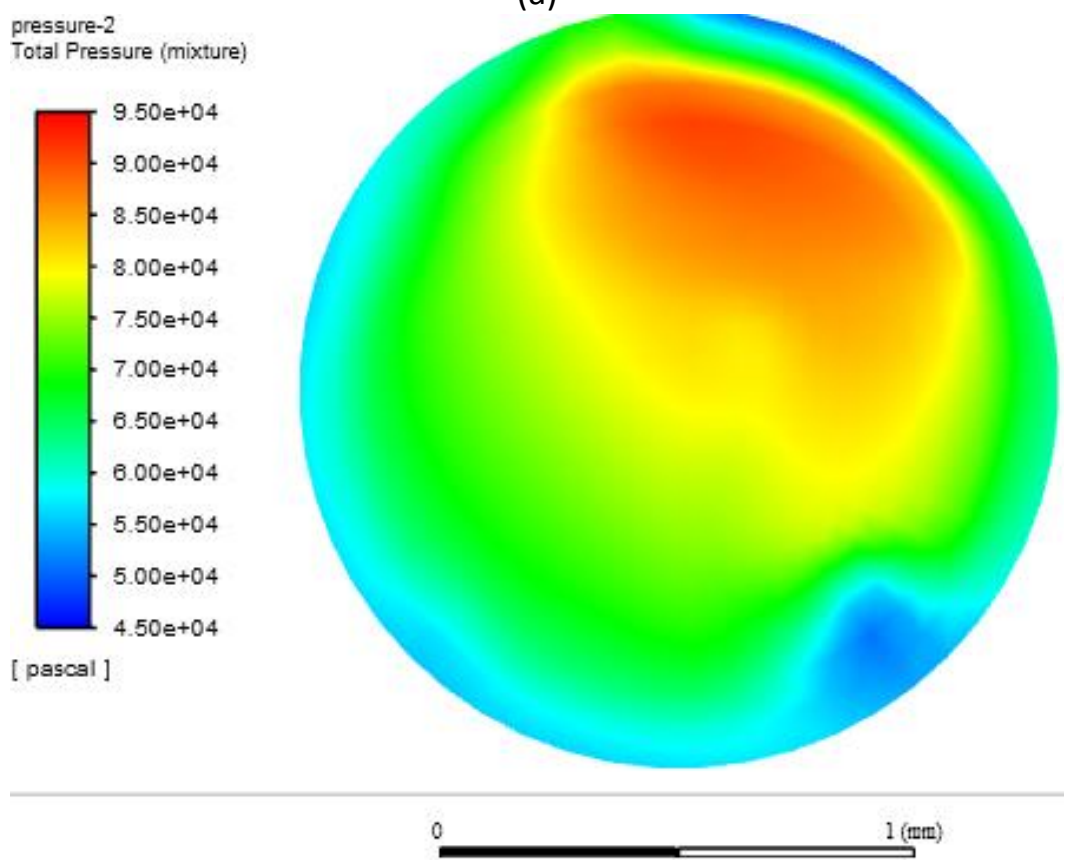

(b)

Fig. 11. The total pressure contour at (a) the beginning of the test section, (b) the end of the test section

Pressure gradients obtained in $2 \mathrm{D}$ simulations have gradient values that tend to increase as $\mathrm{J}_{\mathrm{G}}$ increases. The increase in pressure gradients is fairly consistent, but at $\mathrm{J}_{\mathrm{G}}=24.9 \mathrm{~m} / \mathrm{s}$ and $49.7 \mathrm{~m} / \mathrm{s}$, the pressure gradient increases drastically to $1.6 \mathrm{kPa} / \mathrm{m}$ and $2,4 \mathrm{kPa} / \mathrm{m}$. Increased pressure gradients increase in the $\mathrm{J}_{\mathrm{G}}=74.6 \mathrm{~m} / \mathrm{s}$ variation to $28.7 \mathrm{kPa} / \mathrm{m}$. This means that the pressure gradient changes linearly in the initial variation and changes exponentially in the middle to the end. The results of 2D and $3 D$ simulations on variation $J_{G}=0.1 \mathrm{~m} / \mathrm{s}$ show that $2 D$ simulations can represent physical phenomena of flow pattern formation processes and phase interactions occurring. However, when viewed from the pressure gradient values, the 2D and 3D simulations performed have many different values, namely $26.2 \mathrm{kPa} / \mathrm{m}$ and $462.2 \mathrm{kPa} / \mathrm{m}$. The possibility of pressure gradient was increased in 3D 
simulation due to many physical factors considered in 3D simulation but ignored in 2D simulation. The liquid mixture of $0.9 \%$ sodium chloride and $5 \%$ glucose has a kinematic viscosity almost the same as water, so the difference viscosity did not influence the void fraction and the floe pattern.

It was done a numerical simulation of two-phase flow inside a $3 \mathrm{~mm}$ mini channel. The level-set method was used to capture the liquid-gas interface. In the mini channel, the creation of diverse twophase flow patterns was explored. Three flow patterns were investigated throughout the simulation: bubbly flow and two types of slug flow with short and long slugs. The chaotic nature of slug and bubble sizes has been demonstrated due to unstable flow at the mini channels intake. The distance between the bubbles and slugs changes the unstable flow. According to research, the two-phase flow pattern becomes more stable at low water inlet velocity [16]. In prior work, heat transfer and flow friction of three mini-channel regenerative heat exchangers with channel hydraulic diameters of 1.5, 1 , and $0.5 \mathrm{~mm}$ were investigated using a combined experiment CFD as an alternative to the singleblow method. Because of its higher specific surface area, $0.5 \mathrm{~mm}$ MCRHX had the highest interstitial heat transfer coefficient.

Nusselt number and friction factor correlations were obtained for each arrangement [17]. Heat exchangers are commonly employed in heat transfer between two different fluids separated by a solid wall to save time and money. The heat transfer of a counter-flow helical double pipe heat exchanger was studied in this study using "Ansys CFX" and Computational Fluid Dynamics (CFD). The cold and hot fluids temperatures were $10-20^{\circ} \mathrm{C}$ and $30-50^{\circ} \mathrm{C}$, respectively. The flow Reynolds numbers ranged from 4103 to 42103 , and the process was single-phase. With correlation coefficients of 0.98 and 0.97 for hot and cold streams, respectively, the model explained the experimental results. Furthermore, the wire-insert in the cold flow channel increased fluid turbulence, and the temperature difference between the cold fluid inlet and outflow was proportional to the hot fluid temperature [18].

Computational hemodynamic is an excellent technical and approach tool that helps many doctors obtain a lot of information about the patient's situation in many diseases such as cardiovascular disease, even surgery, etc. The dispersion of blood cells in plasma is heterogeneous. Therefore, blood fluid is a multi-phase mixture of non-Newtonian fluid. Numerical calculations of non-Newtonian viscosity models of blood flow parameters include Reynolds numbers; Heat flux of different walls in three body situations (sleep, standing, and running), and others investigated. To build a 3D model of kidney blood vessels, so an open-source software program using Digital Imaging and Communications in Medicine (DICOM) and Magnetic Resonance Image (MRI) was used. Non-Newtonian blood flow is considered a laminar flow. In different situations, all heat flux produced by the body impacts unidimensional parameters such as pressure drop, average wall shear voltage, heat transfer coefficient, and temperature [19]. In addition, analysis of hemodynamic blood flow in cerebrovascular has become one of the important research topics in bio-mechanics in recent decades. The main task of the brain's blood vessels is to supply glucose and oxygen to the brain (Buxton \&Frank, 1997). It also involves multi-component or multi-phase flow since the blood contains various elements such as glucose, oxygen, and other substances.

Research focusing on MEMS sensor technology has also been developed in Italy in recent years, describing research achievements for health and physical activity, safety, and environmental sensing, in addition to intelligent system integration. Innovative and smart integrated solutions for sensing devices, researched and implemented in Italian research centers [20]. Furthermore, before energy metabolism can take place, brain cells must be supplied with oxygen and glucose. Only then, in combination with normal mitochondrial function, sufficient energy (adenosine triphosphate (ATP)) can be produced. Glucose is the only fuel for the human brain. The brain lacks fuel deposits and requires a continuous supply of glucose and oxygen. Therefore, steady brain blood flow (CBF), 
cerebral oxygen pressure and delivery, and normal mitochondrial function are essential for maintaining brain function and tissue survival [21]. It is also reported that Cerebral blood flow (CBF) or cerebral blood flow and cerebral metabolic rate are usually combined, i.e., increased metabolic needs will lead to increased flow. Research shows that the key mechanism responsible for regional CBF enhancement ( $\mathrm{rCBF}$ ) during functional activation is the close relationship between rCBF and glucose metabolism. The study also confirmed that the release of rCBF and oxidative metabolism is a consequence of increased less noticeable oxygen consumption [22]. Over the past few decades, significant improvements have been made in computational human phantoms (CHP) and biomedical engineering applications. Their sophistication increased dramatically.

The first CHP consisted of simple geometric volumes, e.g., cylinders and spheres. At the same time, the current CHP has a high resolution, covers most of the patient population, has high anatomical accuracy, can be positioned, can change shape, and is coupled with a variety of details to perform enabled computing. Advances in imaging techniques and semi-automatic segmentation tools allow rapid and personalized CHP development. This progress opens the door to rapidly developing personalized CHPs, inherently including patient diseases [23].Industry 4.0 spreads from manufacturing to health care. It has been widely explained about the 4.0 industry revolution in the field of Health care. Examples include Caregiving homes, automated medical production, health care robotics, and human-robot symbiosis [24].

\section{Conclusion}

The significant finding is that the gradient values of pressure gradients in 2D and 3D simulations tend to increase as $J_{G}$ increases. The beginning fluctuation of the pressure gradient is linear, but it changes exponentially from the middle to the end. The findings of the $2 D$ and $3 D$ simulation variants of $J_{G}=0.1 \mathrm{~m} / \mathrm{s}$ show that $2 \mathrm{D}$ simulations may accurately simulate physical processes such as pattern generation and phase interactions. However, the 2D and 3D simulations performed had vastly different results when looking at the pressure gradient values due to various physical elements considered in 3D simulation but overlooked in 2D simulation.

\section{Acknowledgment}

Thanks to the Ministry of Research, Technology, and the Higher Education Republic of Indonesia for the Research Funds on the scheme of PDUPT. I want to express my gratitude to Universitas Muhammadiyah Yogyakarta for the support and laboratory facilities.

\section{References}

[1] Faghri, Amir, and Yuwen Zhang. "Introduction to transport phenomena." Transport Phenomena in Multiphase Systems (2006): 1-106. https://doi.org/10.1016/B978-0-12-370610-2.50006-4

[2] Cavallini, A., D. Del Col, L. Doretti, M. Matkovic, L. Rossetto, and C. Zilio. "Two-phase frictional pressure gradient of R236ea, R134a and R410A inside multi-port mini-channels." Experimental Thermal and Fluid Science 29, no. 7 (2005): 861-870. https://doi.org/10.1016/j.expthermflusci.2005.03.012

[3] Ghorai, Subhashini, and K. D. P. Nigam. "CFD modeling of flow profiles and interfacial phenomena in two-phase flow in pipes." Chemical Engineering and Processing: Process Intensification 45, no. 1 (2006): 55-65. https://doi.org/10.1016/j.cep.2005.05.006

[4] Ekambara, K., Mahesh T. Dhotre, and Jyeshtharaj B. Joshi. "CFD simulations of bubble column reactors: 1D, 2D and 3D approach." Chemical Engineering Science 60, no. 23 (2005): 6733-6746. https://doi.org/10.1016/i.ces.2005.05.047

[5] Lahey Jr, Richard T., and Donald A. Drew. "The analysis of two-phase flow and heat transfer using a multidimensional, four field, two-fluid model." Nuclear Engineering and Design 204, no. 1-3 (2001): 29-44. https://doi.org/10.1016/S0029-5493(00)00337-X

[6] Moraveji, Mostafa Keshavarz, and Reza Mohammadi Ardehali. "CFD modeling (comparing single and two-phase 
approaches) on thermal performance of Al203/water nanofluid in mini-channel heat sink." International Communications in Heat and Mass Transfer $44 \quad$ (2013): $157-164$. https://doi.org/10.1016/i.icheatmasstransfer.2013.02.012

[7] Kandlikar, Satish G., and William J. Grande. "Evolution of microchannel flow passages--thermohydraulic performance and fabrication technology." Heat Transfer Engineering 24, no. 1 (2003): 3-17. https://doi.org/10.1080/01457630304040

[8] Ajayi, N. O., L. Lazarus, E. A. Vanker, and K. S. Satyapal. "Anatomic Parameters of the Left Coronary Artery: an Angiographic Study in a South African Population." International Journal of Morphology 31, no. 4 (2013): 13931398. https://doi.org/10.4067/S0717-95022013000400039

[9] Sharan, Maithili, and Aleksander S. Popel. "A two-phase model for flow of blood in narrow tubes with increased effective viscosity near the wall." Biorheology 38, no. 5, 6 (2001): 415-428.

[10] Sukamta, Sukamta. "Computational fluid dynamics (CFD) and experimental study of two-phase flow patterns gasliquid with low viscosity in a horizontal capillary pipe." CFD Letters 11, no. 8 (2019): 16-23.

[11] Khan, Noor Saeed, Poom Kumam, and Phatiphat Thounthong. "Computational approach to dynamic systems through similarity measure and homotopy analysis method for renewable energy." Crystals 10, no. 12 (2020): 1086. https://doi.org/10.3390/cryst10121086

[12] Khan, Noor Saeed, Auwalu Hamisu Usman, Arif Sohail, Abid Hussanan, Qayyum Shah, Naeem Ullah, Poom Kumam, and Phatiphat Thounthong. "A Framework for the Magnetic Dipole Effect on the Thixotropic Nanofluid Flow Past a Continuous Curved Stretched Surface." Crystals 11, no. 6 (2021): 645. https://doi.org/10.3390/cryst11060645

[13] Zuhra, Samina, Noor Saeed Khan, Muhammad Altaf Khan, Saeed Islam, Waris Khan, and Ebenezer Bonyah. "Flow and heat transfer in water based liquid film fluids dispensed with graphene nanoparticles." Results in Physics 8 (2018): 1143-1157. https://doi.org/10.1016/i.rinp.2018.01.032

[14] Bahnasy, Amal, and A. M. Abdel-Wahab. "Mathematical Model Represents the Effect of Flexible Endoscopy on Suspension Fluid Flow." Journal of Advanced Research in Fluid Mechanics and Thermal Sciences 89, no. 1 (2022): 42-61. https://doi.org/10.37934/arfmts.89.1.4261

[15] Thirupathi, Gurrala, Kamatam Govardhan, and Ganji Narender. "Radiative Magnetohydrodynamics Casson Nanofluid Flow and Heat and Mass Transfer past on Nonlinear Stretching Surface." Journal of Advanced Research in Numerical Heat Transfer 6, no. 1 (2021): 1-21.

[16] Mosdorf, R. "Modelling of two-phase flow in a minichannel using level-set method." In Journal of Physics: Conference Series, vol. 530, no. 1. IOP Publishing, 2014. https://doi.org/10.1088/1742-6596/530/1/012049

[17] Alfarawi, Suliman, Raya Al-Dadah, and Saad Mahmoud. "Transient investigation of mini-channel regenerative heat exchangers." $\quad$ Applied $\quad$ Thermal $\quad$ Engineering $125 \quad$ (2017): https://doi.org/10.1016/i.applthermaleng.2017.07.038

[18] Ghiasi, Pedram, Amar Salehi, Seyed Salar Hoseini, Gholamhassan Najafi, Rizalman Mamat, Balkhaya Balkhaya, and Fitri Khoerunnisa. "Investigation of the Effect of Flow Rate on Fluid Heat Transfer in Counter-Flow Helical Heat Exchanger Using CFD Method." CFD Letters 12, no. 3 (2020): 98-111. https://doi.org/10.37934/cfdl.12.3.98111

[19] Sedeh, Shahab Naghdi, and Davood Toghraie. "The thermal performance of five different viscosity models in the kidney blood vessel with multi-phase mixture of non-Newtonian fluid models using computational fluid dynamics." Archive of Applied Mechanics 91, no. 5 (2021): 1887-1895. https://doi.org/10.1007/s00419-021-01911-7

[20] Ciuti, Gastone, Leonardo Ricotti, Arianna Menciassi, and Paolo Dario. "MEMS sensor technologies for human centred applications in healthcare, physical activities, safety and environmental sensing: A review on research activities in Italy." Sensors 15, no. 3 (2015): 6441-6468. https://doi.org/10.3390/s150306441

[21] Verweij, B. H., G. J. Amelink, and Jan Paul Muizelaar. "Current concepts of cerebral oxygen transport and energy metabolism after severe traumatic brain injury." Progress in Brain Research 161 (2007): 111-124. https://doi.org/10.1016/S0079-6123(06)61008-X

[22] Paulson, Olaf B., Steen G. Hasselbalch, Egill Rostrup, Gitte Moos Knudsen, and Dale Pelligrino. "Cerebral blood flow response to functional activation." Journal of Cerebral Blood Flow \& Metabolism 30, no. 1 (2010): 2-14. https://doi.org/10.1038/icbfm.2009.188

[23] Kainz, Wolfgang, Esra Neufeld, Wesley E. Bolch, Christian G. Graff, Chan Hyeong Kim, Niels Kuster, Bryn Lloyd et al. "Advances in computational human phantoms and their applications in biomedical engineering-a topical review." IEEE Transactions on Radiation and Plasma Medical Sciences 3, no. 1 (2018): 1-23. https://doi.org/10.1109/TRPMS.2018.2883437

[24] Pang, Zhibo, Geng Yang, Ridha Khedri, and Yuan-Ting Zhang. "Introduction to the special section: convergence of automation technology, biomedical engineering, and health informatics toward the healthcare 4.0." IEEE Reviews in Biomedical Engineering 11 (2018): 249-259. https://doi.org/10.1109/RBME.2018.2848518 